\title{
INTERACTIONS BETWEEN SOCIOECONOMIC STATUS AND MENTAL HEALTH OUTCOMES IN THE NIGERIANCONTEXT AMID COVID-19 PANDEMIC: A COMPARATIVE STUDY
}

\author{
Samson F. Agberotimi ${ }^{1}$, Olusola S. Akinsola ${ }^{2}$, Rotimi Oguntayo ${ }^{3}$, Abayomi O. Olaseni ${ }^{3}$ \\ ${ }^{1}$ Lifestyle Diseases Research Entity, North-West University, Mafikeng Campus, South Africa \\ ${ }^{2}$ Department of Psychology, University of Ibadan, Ibadan, Nigeria \\ ${ }^{3}$ Department of Psychology, University of Ilorin, Ilorin, Nigeria
}

\section{Corresponding author}

Dr. Samson F. Agberotimi, Department of Psychology, Faculty of Health Sciences, North West University, Private Bag X2046, Mmabatho, South Africa 2735. Phone: +27656412927 E-mail: femiagberotimi@gmail.com; ORCID iD: https://orcid.org/0000-0002-5643-3249

\begin{abstract}
This study examines the mental health outcomes among the healthcare personnel and the general population and the role of socioeconomic status. Eight hundred and eighty-four (884) residents in Nigeria comprising 382 Healthcare Personnel and 502 general residents aged between 18 and 78 years $(\mathrm{M}=28.75, \mathrm{SD}=8.17)$ responded to an online survey with measures of Impact of Event Scale-Revised (IES-R), Generalized Anxiety Disorder (GAD-7), Patient Health Questionnaire (PHQ-9) and Insomnia Severity Index. Collected data were subjected to statistical analysis using the SPSS v.25. Results revealed significant difference in the prevalence of depressive symptoms $(\chi 2=14.26 ; \mathrm{df}=4 ; \mathrm{p}<0.01)$; insomnia symptoms $(\chi 2=40.21 ; \mathrm{df}=3 ; \mathrm{p}<0.01)$; posttraumatic stress symptoms $(\chi 2=08.34 ; \mathrm{df}=3 ; \mathrm{p}<0.05)$ and clinical anxiety symptoms $(\chi 2=06.71 ; \mathrm{df}=1$; $\mathrm{p}<0.05)$ among healthcare personnel and the general population, with a higher prevalence reported by the healthcare personnel. Further, socioeconomic status significantly influence prevalence of depressive symptoms $\left(\chi_{2}=04.5 ; \mathrm{df}=4 ; \mathrm{p}<0.05\right)$. The study concluded that the prevalence of poor mental health outcomes during the COVID-19 crisis among Nigerians is worrisome. Also, the socioeconomic status of the citizens has serious implications on depressive symptoms. It was recommended that better attention should be paid to the mental health of residents in Nigeria, most especially healthcare workers during the COVID-19 pandemic.
\end{abstract}

Keywords: COVID-19, Mental health, Socioeconomic Status, Healthcare workers, Nigeria. 


\section{INTRODUCTION}

Since the outbreak of coronavirus otherwise known as COVID-19 which was first reported in December 2019 in Wuhan China, declared as Public Health Emergency of International Concern in January 2020 and later a pandemic in March 2020 by the World Health Organisation (WHO), the world has not been the same (WHO, 2020). For instance, the statistics released by the Johns Hopkins University in April 2020 indicated that there had been more than 1,039,000 confirmed cases and 55,000 deaths worldwide. The statistics in Nigeria showed that at the end of April 2020, more than 2,500 cases have been confirmed, while 87 people have died (NCDC, n.d.) Despite the disturbing figures, it has been opined that the actual global incidence rate of COVID19 cases is likely to be far higher than what the statistics show (Flaxman et al., 2020).

Being a novel disease that is highly contagious, spreading fast across the world, and the fact that there is yet to be an established cure for it, COVID-19 pandemic has created a lot of panic in every part of the world. In response, many countries have put up different measures especially those upholding social distancing order to slow down the spread of the disease. Although there is evidence of the effectiveness of quarantine measures to control the spread of infectious diseases such as cholera, severe acute respiratory syndrome (SARS) or Ebola in the past (e.g. Twu et al., 2003), the restriction of movement and lockdown on socioeconomic activities implemented across different countries of the world has generated different opinions about the impact on the general citizens (Barbera et al., 2001).

From the foregoing, emerging evidence has implicated the ongoing COVID-19 pandemic in the mental health outcomes among different populations such as the healthcare professional and the general public worldwide (e.g. Brooks, et al., 2020; Ji, et al., 2017; Lai, et al., 2020; Rossi, et al., 2020). Also, the social-distancing and self-isolation during the COVID-19 pandemic place more challenge on the mental health and general well-being of the people (Mukhtar, 2020). In this regard, Odriozola-González, et al. (2020) observed that amid the COVID-19 crisis and confinement in Spain, a significant proportion of the members of the society present with distressing mental health outcomes including anxiety, depression, and stress. The authors further reported that an increase in the prevalence of psychological distress was significantly associated with female sex and younger age. Similarly, it has been observed that restriction of movements 
and social activities have significantly contributed to increasing in intrapersonal and interpersonal issues such as domestic violence, family dysfunction and poor health outcomes (including suicide) among the adult (Banerjee, 2020; Mamun \& Griffiths, 2020; Mukhtar, 2020; Shi \& Hall, 2020;) and children (Bahn, 2020) populations.

It is crucial to assess the mental health outcomes of people during a global crisis such as the COVID-19 pandemic alongside the socioeconomic status and attributes of the people. This is because several studies have established strong relationships between socioeconomic status (SES) and mental wellbeing. More importantly, low SES have been implicated in poor self-reported mental health including depression, anxiety, sleep problems and psychological distress in adults and adolescents (Richter, et al., 2009; Salami \& Walker, 2014). According to Hutton, et al. (2014) adolescents who rated their family affluence below the average are more likely to report poor mental health compared to their peers with high family affluence. Also, Anders, et al. (2013) reported that people living in an urban environment with a high or medium SES have a greater probability of good sleep quality. In this respect, Holmes, et al. (2020) argued that serious psychological distress is anticipated from potential global economic crisis following the COVID19 pandemic. This argument is substantiated by previous evidence linking the socioeconomic status of the people to their mental health outcome following the SARS epidemic in 2003 (e.g. Kanter \& Manbeck, 2020; Nickell, et al., 2004; Tsang. Et al., 2004; Yip, et al., 2010).

Having a holistic understanding of the mental health outcomes of all members of the society, not only focusing on direct victims (patients) and healthcare providers in response to any major event is crucial to the recovery of the people. This position was emphasized by the proposition of the Canadian National Advisory Committee on SARS and Public Health in 2003 that a 'systemic perspective', focusing on the general population and not just medical staff and patients should be embraced in addressing the SARS epidemic (Naylor, et al., 2003). Nevertheless, Furthermore, the literature shows that many studies addressing the psychological consequences of COVID-19 are focusing exclusively on either the healthcare professionals or the general public, therefore limiting the extent to which comparison between the two populations concerning the mental health outcomes during the COVID-19 crisis. 
Furthermore, the situation in Nigeria calls for special attention because being a developing country where SMEs contribute $48 \%$ of national GDP, account for $96 \%$ of businesses and $84 \%$ of employment (Public Works Corporation, n.d.), the effect of the present COVID-19 pandemic and lockdown on socioeconomic activities is likely to be severe on the well-being of the people, many of whom rely on daily income to cater for their personal and family financial needs. Hence, the significance of this study addresses the interaction between socioeconomic status and mental health outcomes of Nigerians during COVID-19 pandemic cannot be overemphasized. Specifically, the following objectives guided this study:

1. To investigate the interaction between socioeconomic status of respondents and mental health outcomes during the COVID-19 crisis.

2. To examine the comparative analysis of mental health outcome among the healthcare population and the general population amid the COVID-19 crisis.

\section{METHODS}

\section{Design}

An expo facto research design was employed in the study. This design was found applicable to enable investigator rate the psychological distress experienced by participants amid COVID-19 pandemic with manipulation of any variables.

\section{Sampling}

A blend of Respondent-Driven Sampling (RDS) technique and Random Survey Sampling (RSS) were used in this study for healthcare personnel and the general population respectively. RDS was considered appropriate due to the present lockdown and movement restriction which made it very difficult to physically access frontline healthcare personnel at the time of data collection. Key persons across each category of healthcare workers were considered the seed in the study, and therefore, disseminate links to others in the same category to respond to the questionnaire accordingly. RRS was considered appropriate because it enables the dissemination of an online semi-structured questionnaire developed using google forms, with a consent form appended to it. The link of the questionnaire was sent through emails, WhatsApp and other social media to people 
on the contact of the investigators. The prospective respondents were then encouraged to roll out the survey to other residents in Nigeria.

\section{Participants}

Table 1. Socio-demographic Characteristics of the Study Participants

\begin{tabular}{|c|c|c|c|}
\hline Characteristics & $\begin{array}{c}\text { Overall } \\
(\mathbf{N}=\mathbf{8 8 4} / \%) \\
\end{array}$ & $\begin{array}{c}\text { Healthcare Personnel } \\
(n=382 / \%)\end{array}$ & $\begin{array}{c}\text { General Population } \\
(n=502 / \%)\end{array}$ \\
\hline \multicolumn{4}{|l|}{ Sex } \\
\hline Male & $482(54.5)$ & $207(54.2)$ & $269(53.6)$ \\
\hline Female & $402(45.5)$ & $169(44.2)$ & $225(44.8)$ \\
\hline \multicolumn{4}{|l|}{ Religion Affiliation } \\
\hline Christian & $609(68.9)$ & $272(71.2)$ & $337(67.1)$ \\
\hline Islam & $261(29.5)$ & $102(26.7)$ & $159(31.7)$ \\
\hline Others & $14(01.6)$ & $08(2.1)$ & $06(1.2)$ \\
\hline \multicolumn{4}{|l|}{ Ethnicity } \\
\hline Southern, Nigeria & $753(85.2)$ & $319(83.5)$ & $433(86.3)$ \\
\hline Northern, Nigeria & $96(10.9)$ & $44(11.5)$ & $47(9.4)$ \\
\hline Foreigner & $35(4.0)$ & $17(04.4)$ & $22(4.4)$ \\
\hline \multicolumn{4}{|l|}{ Marital Status } \\
\hline Single & $297(33.6)$ & $132(34.6)$ & $165(32.9)$ \\
\hline Married & $577(65.3)$ & $244(63.9)$ & $333(66.3)$ \\
\hline Separated/Divorced & $10(01.1)$ & $06(01.6)$ & $04(0.8)$ \\
\hline \multicolumn{4}{|l|}{ Level of Education } \\
\hline Complete Tertiary Education & $352(39.8)$ & $154(40.3)$ & $198(39.4)$ \\
\hline Incomplete Tertiary Edu. & $236(26.7)$ & $100(26.2)$ & $136(27.1)$ \\
\hline Postgraduate Education & $254(28.7)$ & $108(28.3)$ & $146(29.1)$ \\
\hline Secondary Sch. Education & $42(04.8)$ & $20(05.2)$ & $22(04.4)$ \\
\hline
\end{tabular}

Eight hundred and eighty-four (884) participants that responded to depression, anxiety, posttraumatic stress symptoms, and insomnia scales. The sampled population cut across healthcare personnel and the general population, invariably constituting $43.21 \%(\mathrm{n}=382)$ and $56.79 \%(\mathrm{n}=502)$ of the study respondents respectively. Considering the gender disparity, majority of the respondents were male, constituting $54.5 \%$ of the total respondents, while the female counterparts constituted $45.5 \%$. There was a disparity in the distribution of geographical affiliation of respondents. Majority of the respondents were from the southern part of Nigeria, constituting $85.2 \%$ of the sample, $10.9 \%$ were from the northern part of Nigeria, while $4 \%$ were foreign residents in Nigeria. The disparity across respondents' marital status and level of education were also reported (see table 1). 


\section{Instrument}

Data were collected via an online self-reported questionnaire designed by the investigators. The questionnaire contained six sections related to the mental health outcome of health workers in Nigeria amid coronavirus pandemic. The first section consisted of information assessing demographic attributes such as sex, age, religion, and marital status of participants.

The second section contained the 22-item Impact of Event Scale-Revised (IES-R) by Donna McCabe. The scale was developed to measure the subjective response to a specific traumatic event, especially in the response sets of intrusion, avoidance, and hyperarousal, as well as total subjective stress IES-R score. The IES-R is not meant to be diagnostic. The total IES-R score was divided into 0-23 (normal), 24-32 (mild psychological impact), 33-36 (moderate psychological impact), and >37 (severe psychological impact). Briere, (1997) affirmed the validity and reliability of the scale. Cronbach's alpha 0.82 was established as the reliability coefficient for the scale in this study.

In section three of the questionnaire is the GAD-7 (Spitzer, Kroenke, Williams \& Lowe, 2006) consisting of 7 questions assessing generalized anxiety disorder, focusing on the frequency of symptoms during the preceding 2-week period. The GAD-7 requires approximately 1-2 minutes to administer and for each symptom queried provides the following response options: "not at all," "several days," "over half the days" and "nearly every day" and these are scored, respectively, as $0,1,2$ or 3 . A score ranging from 0 to 21 is obtainable by respondents. Scores of 5, 10, and 15 are taken as the cut-off points for mild, moderate and severe anxiety, respectively. Cronbach's alpha 0.81 was established as the reliability coefficient for the scale in this study.

The fourth section contained the Patient Health Questionnaire (PHQ-9). The PHQ-9 is a nineitem depression scale that has the potential of being a dual-purpose instrument to establish the diagnosis of a depressive disorder, as well as the grade of symptom severity (Kroenke, Spitzer \& Williams, 2001). Statements measuring depressive symptoms such as "little interest/pleasure in doing things" were rated from 0 (not at all) to 3 (nearly every day) by respondents as applicable to them over the past two weeks. PHQ-9 score can range from 0 to 27. The scale has strong psychometric properties (e.g. Botha, 2011) and has been widely used. Cronbach's alpha 0.87 was established as the reliability coefficient for the scale in this study. 
The fifth section contained the Insomnia Severity Index, a 7-item self-report questionnaire assessing the nature, severity, and impact of insomnia. Participants were required to rate their sleep condition in the last 2 weeks as described by each item of the scale. Questions on the ISI cut across the severity of sleep onset, sleep maintenance, and early morning awakening problems, sleep dissatisfaction, interference of sleep difficulties with daytime functioning, noticeability of sleep problems by others, and distress caused by the sleep difficulties. The scale is responded to on a 5point Likert scale with a score ranging from 0 to 4; thus yielding a total score ranging from 0 to 28. The total score is interpreted as follows: the absence of insomnia (0-7); sub-threshold insomnia (8-14); moderate insomnia (15-21); and severe insomnia (22-28). Previous studies have reported adequate psychometric properties for both the English and French versions (e.g. Bastien, Vallières, \& Morin, 2001). Cronbach's alpha 0.78 was established as the reliability coefficient for the scale in this study. 


\section{Procedure}

This was an online study. Participants with access to the internet were invited to participate in the study. Participants with age more than 18 years, able to understand English and willing to give informed consent were included. A link to the survey on Google form was sent to all participants. On receiving and clicking the link the participants got auto directed to the information about the study. A detailed informed consent form was attached at the beginning of the online quest ionnaire and consent was a prerequisite to continue in the survey. Therefore only individuals who gave their consent participated in the study. The data collection was initiated on 20 March 2020 and closed on 19 April 2020. The sampling technique employed allowed the investigators to collect data from across various states of Nigeria. Eight hundred and eighty-four (884) correctly filled questionnaire were recovered through the Google form and processed for statistical analysis.

\section{Data Analysis}

The collected data was analyzed using the SPSS package (version 25). The analyzed data respond to the two research questions stated in the early paragraph. The analyses include prevalence estimate analysis, and chi-square analysis was therefore presented.

\section{RESULTS}

This phase presents the results and interpretation of data collected on the interaction between socioeconomic status and mental health outcomes and further to explore the comparative analysis of clinical outcomes among the healthcare personnel and the general population.

The result that captured the interaction between socioeconomic standard sof respondents on mental health outcomes was further present in table 2.

Table 2. Showing the interaction between Socioeconomic Status of Respondents and the Prevalence of Depression, Insomnia, and Posttraumatic Stress Symptoms and Anxiety in Nigeria $(\mathrm{N}=884)$

\begin{tabular}{lcccccc}
\hline \multicolumn{1}{c}{ Outcome } & $\begin{array}{c}\text { Above Standard Income } \\
(\mathbf{n = 2 0 1 * \% )}\end{array}$ & $\begin{array}{c}\text { Standard } \\
\text { Income } \\
(\mathbf{n = 5 1 6 * \% )}\end{array}$ & $\begin{array}{c}\text { Below Standard } \\
\text { Income } \\
(\mathbf{n = 1 6 7 * \% )}\end{array}$ & $\begin{array}{c}\text { Prevalence Ratio } \\
(\mathbf{9 5 \%} \text { CI) }\end{array}$ & $\chi^{\mathbf{2}}$ & $\mathbf{p}$ \\
\hline Depression & $46(22.8)$ & $155(61.5)$ & $51(20.2)$ & $0.63-4.60$ & 04.05 & $<0.05$ \\
Insomnia & $50(24.9)$ & $122(60.1)$ & $31(15.3)$ & $0.20-1.68$ & 02.38 & $>0.01$ \\
PTSS & $87(43.3)$ & $249(48.3)$ & $80(47.9)$ & $0.53-2.98$ & 01.50 & $>0.05$ \\
Anxiety & $91(45.3)$ & $242(46.9)$ & $79(47.3)$ & $0.49-2.83$ & 00.19 & $>0.05$ \\
\hline
\end{tabular}

Note: Clinical severity in the study outcomes are the reference categories of all variables 
Outcomes of the study (see table 2) revealed that there was a significant difference in the prevalence of depressive symptoms among respondents with different socioeconomic status $(\chi 2=$ 04.5; $\mathrm{df}=4 ; \mathrm{p}<0.05)$. Further, it was found that the prevalence of clinical depressive symptoms was significantly higher among respondents with standard income compared to respondents with the above stand ard and below stand ard incomes (61.5\% versus $22.8 \%$ and $20.2 \%$; $95 \%$ CI, $0.63-$ 4.60; $\mathrm{p}<0.05)$. Further find ings revealed that there was no significant difference in the prevalence of insomnia symptoms among categories of socioeconomic status $(\chi 2=02.38 ; \mathrm{df}=3 ; \mathrm{p}>0.05)$. Though the prevalence of clinical insomnia symptoms was insignificantly higher among respondents with standard income compared to respondents with the above stand ard and below standard incomes $(60.1 \%$ versus $24.9 \%$ and $15.3 \%$; $95 \% \mathrm{CI}, 0.20-1.68 ; \mathrm{p}>0.05)$.

Similarly, study findings revealed that there was no significant difference in the prevalence of Posttraumatic Stress Symptoms (PTSS) among different socioeconomic classes $(\chi 2=01.50$; $\mathrm{df}=$ $3 ; \mathrm{p}>0.05)$. However, the prevalence of posttraumatic symptoms was insignificantly higher among respondents with standard income compared to respondents with the above standard and below standard incomes (48.3\% versus $43.3 \%$ and 47.9\%; 95\% CI, $0.53-2.98$; p > 0.05). Insignificant difference was also reported in the prevalence of clinical anxiety symptoms among classes of socioeconomic status $\left(\chi^{2}=0.19 ; \mathrm{df}=1 ; \mathrm{p}>0.05\right)$. However, the prevalence of anxiety symptoms was insignificantly higher among respondents with standard income compared to respondents with the above stand ard and below standard incomes (46.9\% versus $45.3 \%$ and 47.3 ; $95 \% \mathrm{CI}, 0.49-2.83 ; \mathrm{p}>0.05)$.

Another objective of the study proposed to examine the comparative analysis of mental health outcome among the healthcare population and the general population was presented in table 3 .

Table 3. Prevalence of Depression, Insomnia, and Posttraumatic Stress Symptoms and Anxiety in Healthcare Personnel and General Population $(\mathrm{N}=884)$

\begin{tabular}{lccccc}
\hline \multicolumn{1}{c}{ Outcome } & $\begin{array}{c}\text { Healthcare Personnel } \\
(\mathbf{n = 3 8 2} * \mathbf{0})\end{array}$ & $\begin{array}{c}\text { General Population } \\
(\mathbf{n = 5 0 2} * \mathbf{0})\end{array}$ & Adjusted Prevalence Ratio $(\mathbf{9 5 \%} \mathbf{C I})$ & $\boldsymbol{\chi}^{\mathbf{2}}$ & $\mathbf{p}$ \\
\hline Depression & $134(35.1)$ & $118(23.5)$ & $0.537-1.034$ & 14.26 & $<0.01$ \\
Insomnia & $127(33.2)$ & $76(15.1)$ & $0.289-0.579$ & 40.21 & $<0.01$ \\
PTSS & $201(52.6)$ & $215(42.8)$ & $0.847-1.519$ & 08.34 & $<0.05$ \\
Anxiety & $223(58.4)$ & $249(49.6)$ & $0.719-1.307$ & 06.71 \\
\hline
\end{tabular}

Note: Clinical severity in the study outcomes are the reference categories of all variables 
Responses from eight hundred and eighty-four (884) participants in the study (i.e. both healthcare personal and the general population) were screened for depression, anxiety, insomnia and posttraumatic symptoms constituted the outcome of the analysis. Outcomes of the study (see table 3) revealed that there was a significant difference in the prevalence of depressive symptoms among healthcare personal and the general population $\left(\chi^{2}=14.26 ; \mathrm{df}=4 ; \mathrm{p}<0.01\right)$. Further, it was found that the prevalence of clinical depressive symptoms was significantly higher among healthcare personnel than the general population $(35.1 \%$ versus $23.5 \%$; $95 \% \mathrm{CI}, 0.54-1.03$; p < 0.01$)$. Finding further revealed that there was a significant difference in the prevalence of insomnia symptoms among healthcare personal and the general population $\left(\chi^{2}=40.21\right.$; $\left.\mathrm{df}=3 ; \mathrm{p}<0.01\right)$. Such that, the prevalence of clinical insomnia symptoms was significantly higher among healthcare personnel than the general population $(33.2 \%$ versus $15.1 \%$; $95 \% \mathrm{CI}, 0.29-0.58 ; \mathrm{P}<$ $0.01)$.

Similarly, study findings revealed that there was a significant difference in the prevalence of Posttraumatic Stress Symptoms (PTSS) among healthcare personal and the general population $\left(\chi^{2}\right.$ $=08.34 ; \mathrm{df}=3 ; \mathrm{p}<0.05)$. Such that, the prevalence of posttraumatic symptoms was significantly higher among healthcare personnel than the general population $(52.6 \%$ versus $42.8 \%$; $95 \% \mathrm{CI}$, $0.85-1.52 ; \mathrm{p}<0.05)$. A significant difference was also reported in the prevalence of clinical anxiety symptoms among healthcare personal and the general population $\left(\chi^{2}=06.71 ; \mathrm{df}=1 ; \mathrm{p}<\right.$ 0.05). Such that, the prevalence of anxiety symptoms was significantly higher among healthcare personnel than the general population $(58.4 \%$ versus $49.6 \%$; $95 \% \mathrm{CI}, 0.72-1.31$; $\mathrm{p}<0.05)$.

\section{DISCUSSION}

Nigeria is a developing country with a population of over 200 million people, the majority of whom are youths (The World Bank). Though the country has vast natural and rich minerals resources, the astronomical progression of population growth is not commensurate to the geometrical progression of economic growth, hence, the high rate of unemployment, underemployment and prevalent poverty. There exists a wide socio-economic inequality gap in the country that has occasioned the establishment of subcategorization into economic classes; lower, middle and upper class as it applies in the Nigerian context, otherwise expressed as "below stand income, standard income and above standard income" in this study. 
The novel COVID-19 pandemic has further introduced economic uncertainties and burden on the dwindling Nigerian economy due to the total shutdown of business activities and lockdown of the country. Before the COVID-19 pandemic, the country has a high caseload of depression (Mbamalu, 2019), hence, the expectation of a high prevalence of mental health outcomes among the population due to COVID-19 pandemic. This study found the prevalence of mental health outcomes among the Nigerian population during the COVID-19 pandemic as determined by the different class of socioeconomic status and further reported difference in the prevalence of mental health outcomes between healthcare workers and the general population. In specifics, the study reported a relationship between socioeconomic status and prevalence of clinical depression in Nigeria during the COVID-19; the standard income socioeconomic class reported almost twothirds (62\%) higher prevalence of clinical depression as against the above standard income and below standard income class $(22.8 \%$ vs $20.2 \%)$. Kanter et al. (2020) suggested that a large population may develop inequitably distributed depression due to the stressors of the COVID-19 crisis.

The standard (middle) income socioeconomic class in Nigeria is the largest socioeconomic group, occupying the wide inequality gap between the haves and the haves not. These individuals are mostly business owners (small and medium scale enterprises industry) and major salary earners from the private and government establishments, therefore, they are the most hit by the closure of businesses and lockdown in the country. There is speculation of a looming recession due to the COVID-19 pandemic (The World Bank, 2020), which has spurred some organizations to lay off staff and reduce the salary of the retained staff. These are valid reasons why this group may have reported a higher prevalence of depression compared to the above (high) standard income class who are mostly politicians and big industrialist that have no fear of lay off or reduction in salary and below standard income class who have nothing to lose. Importantly, the above standard income class hold the economic power of the country and economic power translates into political power, thereby giving control of state structure into the hands of the above standard income class. The incursion of the middle class into the upper-class society ensues into cohesion and frustrationaggression that can lead to depression of the standard income class. Consistent with our findings, various studies have confirmed that mental health deteriorates in line with the level of socioeconomic status (Goldman, Glie \&Weinstein, 2018) and economic recessions (Forbes \& Krueger, 2019). 
Pappas (2020) suggested that people with lower socioeconomic status have a higher tendency to have mental health issues. The low socioeconomic level has been associated with death and high illness rates in several studies, regardless of the cause of death being from infectious or noninfectious diseases and indices for measuring socioeconomic status (Kaplan, et al., 2007). Studies from various countries have reported a relationship between socioeconomic status and mental health during COVID-19, but there has been a disparity in the class that is most affected. While our study reported that the standard (middle) income socioeconomic class indicated the highest prevalence of depression during the COVID-19 pandemic, Heath (2020) reported $45 \%$ of the upper socioeconomic status class reported their emotional well-being harmed by coronavirus as against $34 \%$ and $36 \%$ from the lower and middle socioeconomic status class. Consistent with popular opinion, Panchal et al. (2020) reported in a United States tracking poll during COVID-19 that; those living in a shelter reported $10 \%$ higher rate of negative mental health effects than those not sheltering, those affected by layoff reported 14\% higher rate of negative mental health effects than those who still have their jobs and income, and low-income earners reported $13 \%$ higher rate of negative mental health effects than high-income earners and $12 \%$ higher rate of negative mental health effects than middle-income earners.

Similarly, studies unrelated to COVID-19 reported that; lower socioeconomic indicators determined higher depression symptoms in Pakistan (Maselko, et al., 2018), higher-income associated with lower depression in Finland and Poland (Freeman et al., 2016), low socioeconomic position and, increasing distress and decreasing well-being among American adults (Goldman, Glie \&Weinstein, 2018).

Our study further reported prevalence of clinical insomnia, clinical posttraumatic stress symptoms and clinical anxiety among the Nigerian population during COVID-19, but there was no reported difference in the experience of clinical insomnia, clinical posttraumatic stress symptoms and clinical anxiety among the three socioeconomic class. Similar to our findings, studies in China to mental health during COVID-19 reported similar outcomes; depressive symptoms, anxiety symptoms and stress symptoms (Wang et al. 2020; Xiao et al. 2020). High rates of mental health outcomes were also reported among Italian general population: posttraumatic stress symptoms (37\%), depression (17.3\%), anxiety (20.8\%) and insomnia (7.3\%) within three weeks of the lockdown due to COVID-19 (Rossi, et al., 2020). 
This study also found differences in the prevalence of clinical depression, clinical insomnia, clinical posttraumatic stress symptoms and clinical anxiety during the COVID-19 pandemic between healthcare workers and the general population. The prevalence of clinical depression (35.1\% vs $23.5 \%$ ), clinical insomnia (33.2\% vs $15.1 \%$ ), clinical posttraumatic stress symptoms $(52.6 \%$ vs $42.8 \%)$ and clinical anxiety $(58.4 \%$ vs $49.6 \%)$ was higher among the healthcare workers than the general population. The higher rate of mental health outcomes indicated by healthcare workers may be dependent on their role as caregivers and essential workers during the pandemic.

Healthcare workers are essential workers that have to care for the infected despite the impending risk during a pandemic, due to the duty and obligation to care. Compared to the mental health outcomes of the general population that have restricted movement and discontinued working, healthcare workers still go to work, despite the human-to-human transmissible nature of coronavirus, wear uncomfortable personal protective equipment, work overtime, observe directly, the devastation of the virus on their patients. These experiences have a social, emotional and psychological effect on healthcare workers as confirmed in their higher indication of mental health outcomes. In line with our study result, Lai et al. (2020) and Wang, et al. (2020) have it that there was a higher prevalence of mental health outcomes (depression 50.4\%, anxiety $44.6 \%$, insomnia $34 \%$ ) among healthcare workers in China caring for COVID-19 patients compared to the lower prevalence of mental health outcomes (depression $16.5 \%$, anxiety symptoms $28.8 \%$, stress $8.1 \%$ ) reported by the general population in China.

\section{Conclusion}

This study exposed the high prevalence rate of mental health outcomes in Nigeria and indicated a higher prevalence among healthcare workers than the general population. The result also shows the effect of socioeconomic disparity in Nigeria and its effect on mental health.

\section{Limitation of the study}

This study involved relatively few numbers of respondents therefore, this result should be carefully generalized as there is a possibility that outcomes would vary if measured more numbers of participants. Finally, response bias which most times are prevalent in self-report survey study like the present study; it might have influenced the result and limited people's opinion in this study. 


\section{Recommendations}

Looking at the results of the current study, these recommendations are suggested to alleviate the mental health challenges among the residents and health workers during the pandemic period:

1. The government should integrate psychological health services into the fighting against any disease outbreak in the country.

2. Experts in mental health should commence community and media awareness campaign on immediate measures to overcome mental distress amid the present COVID-19 in Nigeria.

3. Palliative measures for economic distress should be objectively discharged to reach out to common people in the communities in Nigeria.

\section{REFERENCES}

Anders, M. P., Breckenkamp, J., Blettner, M., Schlehofer, B., \& Berg-Beckhoff, G. (2013). Association between socioeconomic factors and sleep quality in an urban population-based sample in Germany. European Journal of Public Health, 24(6), 968-973. https://doi.org/10.1093/eurpub/ckt175

Bahn, G. H. (2020). Coronavirus Disease 2019, School Closures, and Children's Mental Health. Journal of the Korean Academy of Child and Adolescent Psychiatry, 31(2), 74-79. https://doi.org/10.5765/jkacap.200010

Banerjee, D. (2020). The COVID-19 outbreak: crucial role the psychiatrists can play. Asian Journal of Psychiatry, 50. https://doi.org/10.1016/j.ajp.2020.102014

Barbera, J., Macintyre, A., Gostin, L., Inglesby, T., O’Toole, T., DeAtley, C., Tonat, K., \& Layton, M. (2001). Large-scale quarantine following biological terrorism in the United States: scientific examination, logistic and legal limits, and possible consequences. JAMA, 286(21), 2711-2717. https://doi.org/10.1001/jama.286.21.2711

Brooks, S. K., Webster, R. K., Smith, L. E., Woodland, L., Wessely, S., Greenberg, N., \& Rubin, G. J. (2020). The psychological impact of quarantine and how to reduce it: rapid review of the evidence. SSRN Electronic Journal. https://doi.org/10.2139/ssrn.3532534

Flaxman, S., Mishra, S., Gandy, A., Unwin, H., Coupland, H., Mellan, T., \& Bhatt, S. (2020). Estimating the number of infections and the impact of non-pharmaceutical interventions on COVID-19 in 11 European countries. https://doi.org/10.25561/77731

Forbes, M. K., \& Krueger, R. F. (2019). The great recession and mental health in the United States. SAGE Journals, 7(5), 900-913.https://doi.org/10.1177/2167702619859337 
Freeman, A., Tyrovolas, S., Koyanagi, A., Chatterji, S., Leonardi, M., Ayuso-Mateos, J. L., Tobiasz-Adamczyk, B., Koskinen, S., Rummel-Kluge, C., \& Haro, J. M. (2016). The role of socio-economic status in depression: Results from the COURAGE (aging survey in Europe). BMC Public Health, 16,(1)._https://doi.org/10.1186/s12889-016-3638-0

Goldman, N., Glei, D. A., \& Weinstein, M. (2018). Declining mental health among disadvantaged Americans. Proceedings of the National Academy of Sciences of the United States of America, 115(28): 7290-7295. https://doi.org/10.1073/pnas.1722023115

Heath, S. (2020, April 2). Socioeconomic status tied to mental health during Coronavirus. Patient Engagement Hit. https://patientengagementhit.com/news/socioeconomic-status-tied-tomental-health-during-coronavirus

Holmes, E. A., O’Connor, R. C., Perry, V. H., Tracey, I., Wessely, S., Arseneault, L., Ballard, C., Christensen, H., Silver, R. C., Everall, I., Ford, T., John, A., Kabir, T., King, K., Madan, I., Michie, S., Przybylski, A. K., Shafran, R., Sweeney, A., Worthman, C. M., Yardley, L., Cowan, K., Cope, C., Hotopf, M., \& Bullmore, E. D. (2020). Multidisciplinary research priorities for the COVID-19 pandemic: a call for action for mental health science. Lancet Psychiatry. https://doi.org/10.1016/ S2215-0366(20)30168-1

Hutton, K., Nyholm, M., Nygren, J. M., \& Svedberg,P. (2014). Self-rated mental health and socioeconomic background: a study of adolescents in Sweden. BMC Public Health, 14, 394, 18. https://doi.org/10.1186/1471-2458-14-394

Ji, D., Ji, Y. Duan, X., Li, W., Sun, Z., Song, X., Meng, Y., Tang, H., Chu, F., Niu, X., Chen, G., Li, J., \& Duan, H. (2017). Prevalence of psychological symptoms among Ebola survivors and healthcare workers during the 2014-2015 Ebola outbreak in Sierra Leone: a crosssectional study. Oncotarget, 8 (8), 12784-12791. https://doi.org/10.18632/oncotarget.14498

Johns Hopkins University \& Medicine. (2020). Coronavirus COVID-19 Global Cases by the Center for Systems Science and Engineering at Johns Hopkins. Retrieved April 3, 2020, from https://coronavirus.jhu.edu/map.html

Kanter, J., \& Manbeck, K. (2020, April 1). COVID-19 could lead to an epidemic of clinical depression, and the health system isn't ready for that, either. The Conversation. https://theconversation.com/covid-19-could-lead-to-an-epidemic-of-clinical-depression-andthe-health-care-system-isnt-ready-for-that-either-134528

Kaplan, G. A., Haan, M. N., Syme, L., Minker, M., \& Winkleby, M. (2007). Socioeconomic status and health. Closing the Gap, 125-129.

Lai, J., Ma, S., Wang, Y., Cai, Z., Hu, J., Wei, N., Wu, J., Du, H., Chen, T., Li, R., Tan, H., Kang, L., Yao, L., Huang, M., Wang, H., Wang, G., Liu, Z., \& Hu, S. (2020). Factors associated with mental health outcomes among healthcare workers exposed to coronavirus disease 2019. JAMA Network Open, 3(3). https://doi.org/10.1001/jamanetworkopen.2020.3976 
Mamun, M. A., \& Griffiths, M. D. (2020). First COVID-19 suicide case in Bangladesh due to fear of COVID-19 and xenophobia: Possible suicide prevention strategies. Asian Journal of Psychiatry, https://doi.org/10.1016/j.ajp.2020.102073.

Maselko, J., Bates, L. Bhalotra, S., Gallis, J. A., O’Donnell, K., Sikander, S., \& Turner, E. L. (2018). Socioeconomic status indicators and common mental disorders: Evidence from a study of prenatal depression in Pakistan. SSM - Population Health, 4, 1-9. https://doi.org/10.1016/j.ssmph.2017.10.004

Mbamalu, S. (2019, October 2). Nigeria has a mental problem. Aljazeera. https://www.aljazeera.com/ajimpact/nigeria-mental-health-problem-191002210913630.html

Mukhtar, S. (2020). Pakistanis' Mental Health during the COVID-19. Asian Journal of Psychiatry, https://doi.org/10.1016/j.ajp.2020.102127

Naylor, D., Basrur, S., Bergeron, M. G., Brunham, R. C., Butler-Jones, D., \& Dafoe, G. (2003). Learning from SARS: Renewal of public health in Canada. Ottowa, Canada: National Advisory Committee on SARS and Public Health.

NCDC (2020). https://covid19.ncdc.gov.ng/ accessed (May 03 2020)

Nickell, L. A. (2004). Psychosocial effects of SARS on hospital staff: survey of a large tertiary care institution. Canadian Medical Association Journal, 170 (5), 793798. https://doi.org/10.1503/cmaj.1031077

Odriozola-González, P., Planchuelo-Gómez, A., Irurtia-Muñiz, M. J., \& de Luis-García, R. (2020). Psychological symptoms of the outbreak of the COVID-19 crisis and confinement in the population of Spain. (preprint version).

Panchal, N., Kamal, R., Orgera, K., Cox, C., Garfield, R., Hamel, L., Munana, C., \& Chidambaram, P. (2020, April 21). The implication of COVID-19 for mental health and substance abuse. KFF. https://www.kff.org/health-reform/issue-brief/the-implications-ofcovid-19-for-mental-health-and-substance-use/

Pappas, S. (2020, April 6). How will people react to the new financial crisis? American Psychological Association. https://www.apa.org/news/apa/2020/04/financial-crisis-covid$\underline{19}$

Public Works Corporation. (n.d.). Assessing current market conditions and business growth prospects. https://www.pwc.com/ng/en/events/nigeria-sme-survey.html

Richter, M., Erhart, M., Vereecken, C. A., Zambon, A., Boyce, W., \& Gabhainn, S. N. (2009). The role of behavioural factors in explaining socio-economic differences in adolescent health: a multilevel study in 33 countries. Social Science and Medicine, 69 (3), 396-403. https://doi.org/10.1016/j.socscimed.2009.05.023

Rossi, R., Socci, V., Talevi, D., Mensi, S., Niolu, C., Pacitti, F., Di, Marco, A. D., Rossi, A., Siracusano, A., \& Lorenzo, G. D. (2020). COVID-19 pandemic and lockdown measured 
impact on mental health among the general population in Italy. An N=18147 web-based survey. https://doi.org/101101/2020.04.09.20057802

Salami, T. K., \& Walker, R. L. (2014). Socioeconomic Status and Symptoms of Depression and Anxiety in African American College Students: The Mediating Role of Hopelessness. Journal of Black Psychology, 40(3), 275-290. https://doi.org/10.1177/0095798413486158

Shi, W., \& Hall, B. J. (2020). What can we do for people exposed to multiple traumatic events during the coronavirus pandemic? Asian Journal of Psychiatry, 51, 102065. https://doi.org/10.1016/j.ajp.2020.102065

The World Bank. (2020, April 9). COVID-19 (Coronavirus) drives Sub-Saharan Africa toward first recession in 25 years. https://www.worldbank.org/en/news/pressrelease/2020/04/09/covid-19-coronavirus-drives-sub-saharan-africa-toward-first-recession-in$\underline{25 \text {-years }}$

Tsang, H. W., Scudds, R. J., \& Chan, E. Y. (2004). Psychosocial impact of SARS. Emerging Infectious Diseases, 10 (7), 1326-1327. http://dx.doi.org/10.3201/eid1007.040090

Twu, S.-J., Chen, T.-J., Chen, C.-J., Olsen, S. J., Lee, L.-T., Fisk, T., \& Dowell, S. F. (2003). Control measures for severe acute respiratory syndrome (SARS) in Taiwan. Emerging Infectious Diseases, 9(6), 718-720. https://doi.org/10.3201/eid0906.030283

Wang, C., Pan, R., Wan, X., Tan, Y., Xu, L., Ho, C. S., \& Ho, R. C. (2020). Immediate psychological responses and associated factors during the initial stage of the 2019 Coronavirus Disease (COVID-19) epidemic among the general population in China. International Journal of Environmental Research and Public Health. 17(5), 1729. https://doi.org/ 10.3390/ijerph17051729.

World Health Organization (2006). WHO-aims report on mental health system in Nigeria. https://www.who.int/mental health/evidence/nigeria who aims report.pdf

World Health Organisation (2020). Advice and guidance from WHO on COVID-19. Retrieved from: https://www.who.int/emergencies/diseases/novel-coronavirus-2019

Yip, P. S., Cheung, Y. T., Chau, P. H., \& Law, Y. W. (2010). The impact of epidemic outbreak: the case of severe acute respiratory syndrome (SARS) and suicide among older adults in Hong Kong. Crisis, 31 (2), 86-92. https://doi.org/10.1027/0227-5910/a000015 